\title{
Measuring Disease Frequency in the Marshfield Epidemiologic Study Area (MESA)
}

\author{
Robert T. Greenlee, PhD, MPH, Epidemiology Research Center, Marshfield Cinic Research Foundation, Marshfield, Wisconsin
}

\begin{abstract}
The Marshfield Epidemiologic Study Area (MESA) is a rare resource for population-based health and medical research developed at Marshfield Cinic Research Foundation. Because of high population coverage and health event capture, MESA is particularly useful for determining the frequency of disease in the general population. A substantial proportion of MESA-based publications appearing in the peer reviewed literature have reported incidence or prevalence rates of disease or disease related factors. This paper reviews the first 10 years of MESA's support of meaningful inquiry into the frequency of disease occurrence, and briefly reports on the data and methods used for such calculations using selected chronic diseases as examples. Limitations of MESA estimates are discussed as are alternate methods. Compared to limited data published for the selected conditions, occurrence rates in MESA based on diagnostic codes and general validation rules only appear somewhat high, although the observed temporal trends and relationships with demographics are consistent. Rich clinical data sources are available to be linked with MESA to improve the specificity of case ascertainment, as is typically done for disease-specific publications from MESA.
\end{abstract}

\section{INTRODUCTION}

The focus of epidemiology is to study the frequency, distribution and determinants of disease. ${ }^{1}$ Measuring the frequency of a disease in the general population and identifying how disease occurrence may differ over time or among population subgroups are important steps in discovering potential causes and determining effective methods for prevention, control and care. ${ }^{2}$ The accurate evaluation of disease occurrence is facilitated by the presence of a geographically defined population base as well as rich sources of health data for the population under study. Marshfield Epidemiologic Study Area (MESA), a resource for population-based health and medical research, provides a rare combination of both components, and consequently has developed a track record of supporting meaningful inquiries into the occurrence of disease. MESA was developed at Marshfield Cinic Research Foundation (MCRF).

This paper highlights and reviews the contributions of MESA-based research to scientific knowledge through the study of disease occurrence over the past 10 years. Also, the paper demonstrates the methods by which the MESA system can support determination of disease frequency through calculation of disease incidence and prevalence for selected chronic diseases.

RECEIVED: AUGUST 6, 2003

REPRINT REQUESTS:

Robert T. Greenlee, PhD, MPH

Epidemiology Research Center

Marshfield Cinic Research Foundation

1000 North Oak Avenue

Marshfield, WI 54449

Telephone: 715-389-3537

Fax: $715-389-3880$

Email: greenlee.robert@mcrf.mfldclin.edu
REVISED AND ACCEPTED: SEPTEMBER 19, 2003

KEYWORDS:

Epidemiology; Wisconsin/epidemiology; Rural population; Incidence; Prevalence; International Classification of Diseases 


\section{MARSHFIELD EPIDEMIOLOGIC STUDY AREA}

Marshfield Clinic is a multi-specialty group practice with more than 700 physicians providing integrated, comprehensive care at 40 clinic sites throughout central and northwestern Wisconsin. Marshfield Clinic is a major provider of care in its 29-county primary service area. MESA was developed in 1991 to facilitate population-based medical research. The majority of residents within the 24 zip codes covered by MESA choose to receive care from Marshfield Clinic and affiliated hospitals. Residency in the region is tracked on a daily basis using Marshfield Clinic administrative files (births, deaths, new patients, changes of address, and health plan enrollment changes), and is supplemented periodically with quality control surveys and public-use data sources for assistance in documenting migration out of the area. The residency archive allows accrual of individual follow-up time, and identification of full population counts and sampling frames at various points in time.

MESA Central contains 14 zip codes. These zip codes surround the main campus of Marshfield Clinic, located in Marshfield, Wisconsin (figure 1). MESA North contains 10 zip codes that encompass several of Marshfield Clinic's regional centers located in Northern Wisconsin (Park Falls, Phillips, Ladysmith and Bruce) (figure 1). According to the 2000 United States Census, the population living in MESA was 77,280 . Marshfield is the only city in the region, accounting for approximately $25 \%$ of the MESA population. The remainder of the region is rural and includes small towns, villages, farmland and open countryside. The white non-Hispanic population of MESA (97\%) reflects the population of central and northwestern Wisconsin.

The high population and health event coverage in MESA are validated periodically through random sample surveys and comparisons with state and national data sources. Past validation results have been previously reported. ${ }^{3}$ MESA

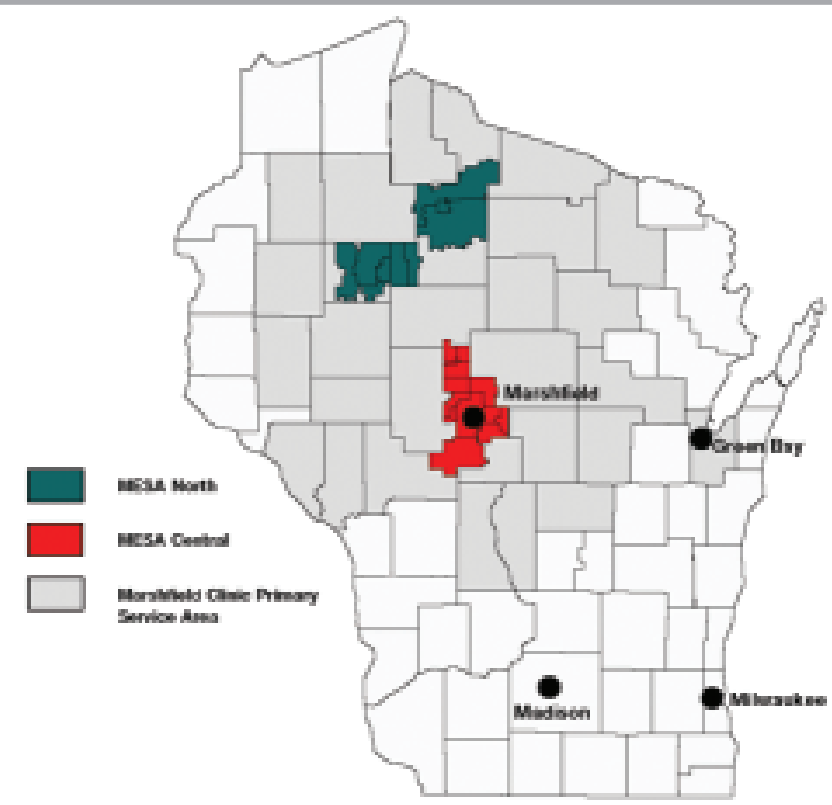

Figure 1. Marshfield Epidemiologic Study Area. validation efforts from the year 2000 continue to show high levels of coverage, indicating that Marshfield Clinic data systems capture more than $97 \%$ of residents, $99 \%$ of deaths, $95 \%$ of hospital discharges and $90 \%$ of outpatient visits in MESA Central. Coverage in MESA North is slightly lower; more than $91 \%$ of residents, $97 \%$ of deaths, $87 \%$ of hospital discharges and $86 \%$ of outpatient visits are captured.

\section{PUBLISHED REPORTS OF DISEASE FREQUENCY IN MESA}

To date, 36 MESA-based publications have appeared in the peer reviewed literature. These publications cover a wide range of clinical and public health topics. Nearly two-thirds of the published works have generated, presented and evaluated estimates of the frequency of disease (or of disease-related factors) in the general population, some of which were not available from any other source. While not all MESA-based publications have reported frequency rates, the identification of incident or prevalent case cohorts, along with corresponding population-based comparison groups when necessary, have often allowed further investigation into potential predictors of disease, the clinical course of illness, and disease outcomes.

The first MESA-based research to appear in print was a 1994 report in the public health literature. ${ }^{4}$ Nordstrom and colleagues briefly introduced the newly developed MESA system and demonstrated the capacity of this rare "epidemiological laboratory" to conduct surveillance of medical care utilization for major chronic diseases, identifying interesting differences in utilization rates by gender and health insurance status. Also during this early period, the seminal paper describing the infrastructure and methods of the MESA system was published in the clinical epidemiology literature. ${ }^{3}$ In this paper, DeStefano and colleagues further demonstrated the capacity of MESA by generating incidence rates of coronary heart disease among MESA women. These rates were found to compare reasonably well with results from other rare sources for such data, including the Framingham Heart study. Another of the earliest papers utilized the population-based nature of MESA to explore the generalizability of studies conducted at tertiary care medical centers. ${ }^{5}$ Layde and colleagues calculated eligibility rates for a recently conducted multi-center clinical study and also compared eligible patients from the general population of MESA with those who participated in the actual project. This report demonstrated the need for caution when interpreting results of clinical and epidemiological studies that are not population-based.

MESA publications during the first several years were dominated by the surveillance and study of injuries associated with agricultural exposures. In order to successfully quantify the incidence of farm injuries, researchers created an active, prospective surveillance system to identify and characterize injury events in the region. This prospective surveillance system was created with the cooperation of Saint Joseph's Hospital Emergency Department (Marshfield, Wisconsin), 
Marshfield Clinic Urgent Care, and non-affiliated community providers of chiropractic care. Researchers also identified and enumerated individuals at risk for farm injury by creating the first Farm Resident Cohort within MESA, which included nearly 5,000 people living on more than 1,500 farms.

A series of seven papers by Layde, Stueland, Nordstrom and colleagues examined the incidence of and risk factors for all farm injuries, among women and the elderly; $6-9$ and for farm injuries due to falls, animals and machinery. ${ }^{10-12}$ These studies reached and informed readers of the agricultural health, occupational medicine and epidemiological literature. The primary focus was to identify strategies for injury prevention and improving farm safety. Linking active injury surveillance with the MESA population also allowed descriptive studies of injuries due to football ${ }^{13}$ and roller sports. ${ }^{14}$ Both studies reported that some types of injuries, when compared to national data, occurred more frequently than expected in MESA.

Since 1998, there has been an expansion in the application of MESA to a broader range of conditions. Clinical researchers at Marshfield were able to generate the very first estimates of the general population occurrence of two important cardiac dysrhythmias: paroxysmal supraventricular tachycardia ${ }^{15}$ and atrial flutter. ${ }^{16}$ As an example of additional opportunities afforded by identifying an incident cohort, Vidaillet and colleagues have recently built upon their earlier work by comparing the cohort of incident cases of atrial flutter to matched population controls, and were among the first to determine that atrial flutter appears to be an independent predictor of mortality. ${ }^{17}$ Another Marshfield clinical researcher assessed the incidence of seizures among older residents of MESA in a prospective fashion and described potential causes, treatments and quality of life among patients following a first seizure. ${ }^{18}$

Nordstrom and coauthors ${ }^{19}$ published one of only two studies in the world on the incidence of carpal tunnel syndrome. They demonstrated substantial increases in the incidence of carpal tunnel syndrome over the 20 years following the publication of the other population-based estimates. Similarly, Greenlee and colleagues presented one of the few population-based reports of myocardial infarction incidence and demonstrated a continued need for primary prevention given non-declining incidence trends over the past decade and a high proportion of cases detected only through death certificates. ${ }^{20}$ Belongia and colleagues presented seroprevalence rates for antibodies against selected bacterial causes of diarrhea among farm and non-farm children in MESA, as well as incidence rates of clinically detected diarrhea in these groups. The results suggest that a reduced ongoing risk of clinical disease among farm children may in part be due to repeated antigenic stimulation by the pathogens. ${ }^{21}$

While the MESA cohort in some circumstances allows determination of disease occurrence rates when other data sources are not available, MESA incidence data can also be used to evaluate the completeness of existing surveillance systems. For example, probable Lyme disease cases in MESA were identified through medical record review and compared to cases tracked by the notifiable disease reporting system for the state of Wisconsin. ${ }^{22}$ The project demonstrated substantial underreporting of cases to the state. However, the project also concluded that the state system monitored time trends, and age and gender differences fairly well.

In addition to rates of disease, MESA has also been informative for determining the population frequency of factors that may cause or prevent disease. For example, Eaker and colleagues studied cervical cancer screening rates among all women in MESA by hysterectomy status and type. They identified direct implications for improving the efficiency and targeting of clinical prevention efforts for cervical cancer. ${ }^{23}$ Also, researchers reported incidence and prevalence rates of selected chronic diseases among rural women in MESA based on the Rural Women's Health Study. ${ }^{24}$ A separate paper by McCarty and others demonstrated high prevalence rates of several key cardiovascular disease risk factors (hypertension, obesity and physical inactivity) among the same women. ${ }^{25}$ Finally, in a recent study with direct national implications, Naleway and colleagues presented prevalence rates of atopic dermatitis and eczema in MESA. They estimated the corresponding proportion of the general population for which pre-exposure smallpox vaccination would be contraindicated because of the increased risk of a serious vaccine complication-eczema vaccinatum-in themselves or their household contacts. ${ }^{26}$ The study went on to survey the prevalent cohort of atopic dermatitis cases in MESA and determined that approximately $40 \%$ of respondents were not aware of their history of this vaccine-contraindicating condition, and concluded that pre-vaccination screening by self-report alone may not be fully effective.

\section{METHODS}

Research in MESA is typically initiated through linking the MESA residency data file, which identifies approximate dates that cohort members enter and depart the selected region, with Marshfield Clinic's extensive archive of medical information. This archive includes a full electronic medical record dating back to the early 1990s; several enhanced clinical registries; files of all procedures, insurance claims and lab results back to 1985; and a file of more than 72 million patient diagnoses dating back to 1960 . To demonstrate the methods by which MESA can support estimation of disease occurrence in the general population, four chronic conditions were selected (colon cancer, chronic renal failure, rheumatoid arthritis, and diabetes). Codes from the International Classification of Disease, 9th revision, (ICD-9) were used to identify the diagnostic events. These codes have been used at Marshfield Clinic since 1979. A file of all diagnosis records from 1979 to 2000 containing the ICD-9 codes of interest was obtained for anyone who had lived in MESA at any time. A general validation algorithm, which required the diagnosis to have been made on at least two occasions, was applied to improve the specificity of the ICD-9 code-based case definitions. 
Incidence can be defined as the rate at which new cases are occurring in the population. Given the data source, incidence in this study measures the rate at which new cases are being clinically detected and diagnosed. For each condition, the date of first inpatient or outpatient diagnosis determined the incident date. Patients with an incident date before 1992 were excluded from the incidence analysis. Incident dates from 1992 to 2000 were then compared to MESA residency periods for the corresponding cohort member to determine if the incident event occurred while they resided in MESA. Only incident events occurring while the patient lived in MESA were considered cases. The count of cases stratified by gender and age at diagnosis became the numerators for incidence rate calculations. The denominators were based on summation of accrued person-time at risk in the MESA population within each age and gender strata. Person-time at risk accrues until an individual is diagnosed with the condition, leaves the population due to migration or death, or until the end of the study period. Overall and age-specific incidence rates were calculated for the entire period, 19922000. Incidence rates were age-adjusted to the 2000 United States standard population using the direct method. ${ }^{27}$ Large sample confidence intervals for the rates were estimated by assuming the incident counts in the population were distributed as Poisson random variables. ${ }^{27}$ Temporal trends over the study period were assessed using 3-year rates to reduce random variation.

For prevalence, all people living in the MESA region on December 31, 2000 were selected from the MESA residency data file, and any archived diagnosis containing the codes of interest were obtained for that group. Prevalence calculations were stratified by gender and age as of December 31, 2000. The numerator for each calculation equaled the number of people with a history of the diagnosis on or before the prevalence date, and the denominator was the count of total MESA residents in that age- and gender-specific stratum. Prevalence rates (actually proportions) were age-adjusted to the 2000 United States Standard population using the direct method. ${ }^{27}$ Large sample confidence intervals were estimated by assuming the prevalence proportions were distributed as binomial random variables. ${ }^{27}$

\section{RESULTS}

Table 1 shows the number of incident diagnosis events in MESA from 1992 to 2000 for each selected condition, as well as the corresponding age-adjusted incidence rate dur- ing this period, expressed in cases per 100,000 person-years (or persons per year). Also included in table 1 is the age-adjusted point prevalence per 1,000 persons based upon a history of past diagnosis with the selected conditions. Figures 2 through 5 show the age-specific incidence rate curves for the selected conditions for males and females separately. Different relationships between age and incidence are evident, as rates of rheumatoid arthritis increase fairly steadily through life, while colon cancer and renal failure increase more sharply in older age groups. The incidence of diagnosed diabetes in MESA increased only through age 65 to 74 years and then declined. Incident diagnosis rates are higher among men at nearly every age for colon cancer, chronic renal failure and diabetes, whereas rheumatoid arthritis occurs more frequently among women at all ages.

Figures 6 and 7 show temporal trends in 3-year incidence rates over a 9-year period. Modest declines were observed for colon cancer and rheumatoid arthritis diagnoses, whereas incidence rates of renal failure and diabetes diagnoses increased somewhat during the study period. Figure 8 indicates that, for diabetes and colon cancer, age-adjusted prevalence is similar by gender, despite higher male incidence rates, likely reflecting the influence of greater numbers of women at older ages when incidence rates are higher. Renal failure is slightly more common among men, but rheumatoid arthritis is considerably more common among females with an age-adjusted rate ratio compared to males of greater than 2 .

\section{DISCUSSION}

The incidence and prevalence of clinically detected disease presented in this paper to demonstrate MESA-based methods compare fairly well with previously reported data in the medical literature, although MESA rates are somewhat higher in general. For example, colon cancer incidence rates for ages 45 to 75 in MESA are somewhat higher than rates among whites in the National Cancer Institute's Surveillance, Epidemiology, and End Results (SEER) program of population-based cancer registries. The modest decline in incidence over time however, is compatible with the secular trend observed in SEER data. ${ }^{28}$ Likewise, the incidence and prevalence of rheumatoid arthritis are higher in MESA than rates previously reported from Europe, but the age and gender patterns, as well as the decline over time are quite similar. ${ }^{29}$ Data on chronic renal failure are more difficult to obtain, although incidence rates of this diagnosis in MESA are somewhat higher than reported rates of serious chronic

Table 1. Incidence and Prevalence of Selected Diagnoses, Marshfield Epidemiologic Study Area (MESA).

\begin{tabular}{|c|c|c|c|c|c|c|c|}
\hline \multirow[b]{2}{*}{ Disease } & \multirow[b]{2}{*}{ ICD-9 Codes } & \multicolumn{3}{|c|}{$\begin{array}{l}\text { INCIDENCE* (1992-2000) } \\
\text { Rate per } 100,000\end{array}$} & \multicolumn{3}{|c|}{$\begin{array}{l}\text { PREVALENCE* }(\mathbf{1 2 / 3 1 / 0 0 )} \\
\text { Prevalence per } 1,000\end{array}$} \\
\hline & & Cases & person-years & $95 \% \mathrm{Cl}$ & Cases & persons & $95 \% \mathrm{Cl}$ \\
\hline Colon Cancer & $153.0-153.9$ & 379 & 47.7 & $(42.8,52.5)$ & 336 & 3.3 & $(3.0,3.7)$ \\
\hline Chronic Renal Failure & 585.X & 441 & 53.8 & $(48.7,58.9)$ & 234 & 2.4 & $(2.1,2.8)$ \\
\hline Rheumatoid Arthritis & $714.0-714.9$ & 570 & 77.9 & $(71.4,84.4)$ & 986 & 10.6 & $(9.9,11.2)$ \\
\hline Diabetes & $250.0-250.9$ & 2997 & 451.3 & $(435.0,467.6)$ & 4068 & 43.7 & $(42.5,45.0)$ \\
\hline
\end{tabular}

${ }^{*}$ Age-adjusted to the 2000 United States standard population 


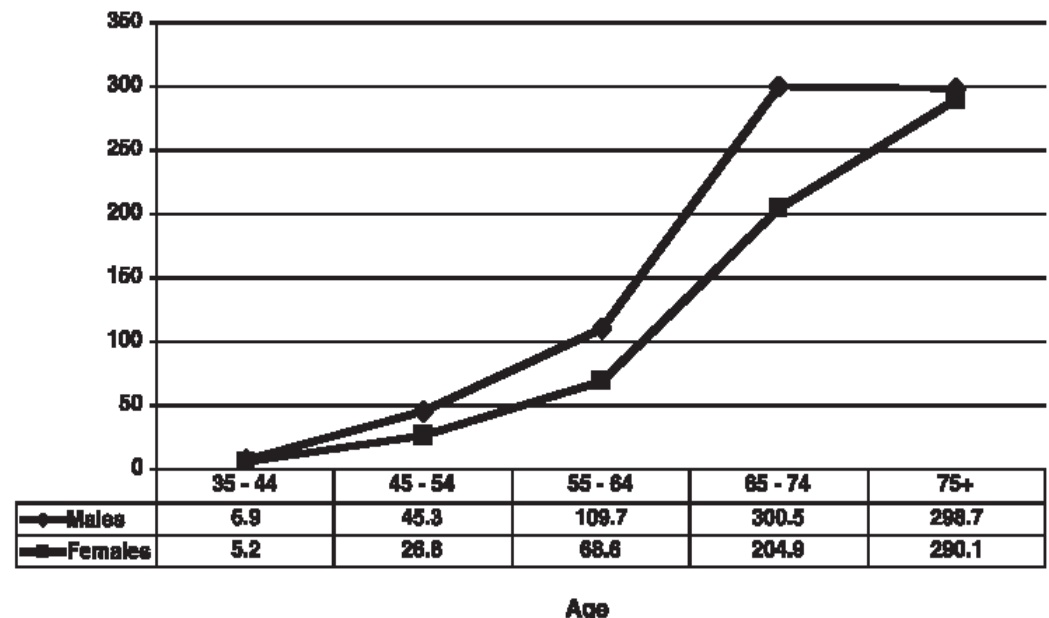

Figure 2. Age-specific incidence of diagnosis with colon cancer, MESA, 1992-2000, by gender.

\section{Rate per 100,000}

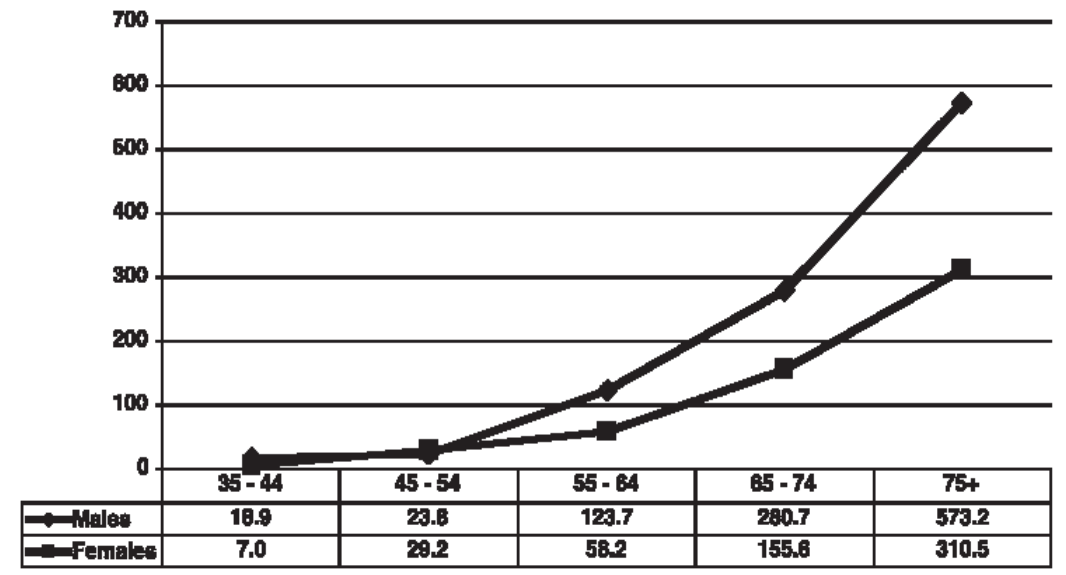

Aos

Figure 3. Age-specific incidence of diagnosis with chronic renal failure, MESA, 1992-2000, by gender.

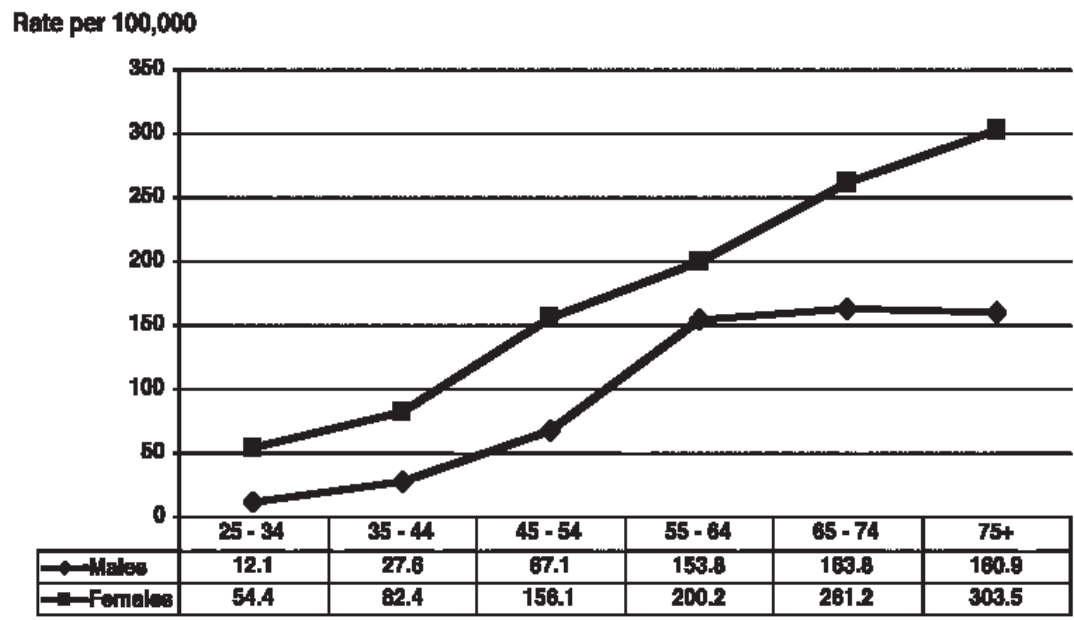

Age

Figure 4. Age-specific incidence of diagnosis with rheumatoid arthritis, MESA, 1992-2000, by gender. 
Rate per 100,000

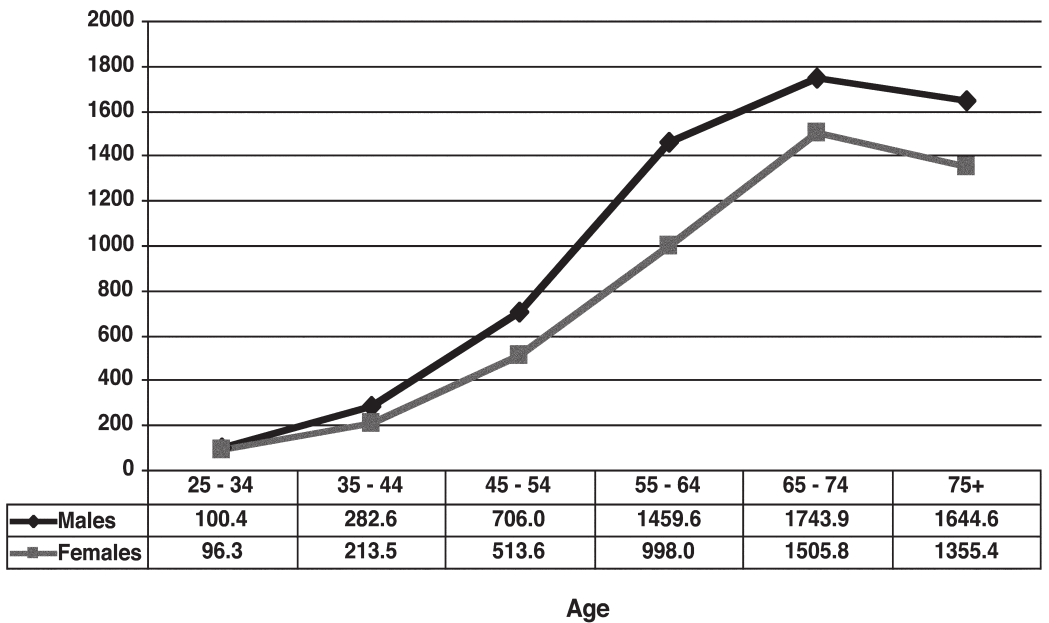

Figure 5. Age-specific incidence of diagnosis with diabetes, MESA, 1992-2000, by gender.

Rate per $100,000 *$

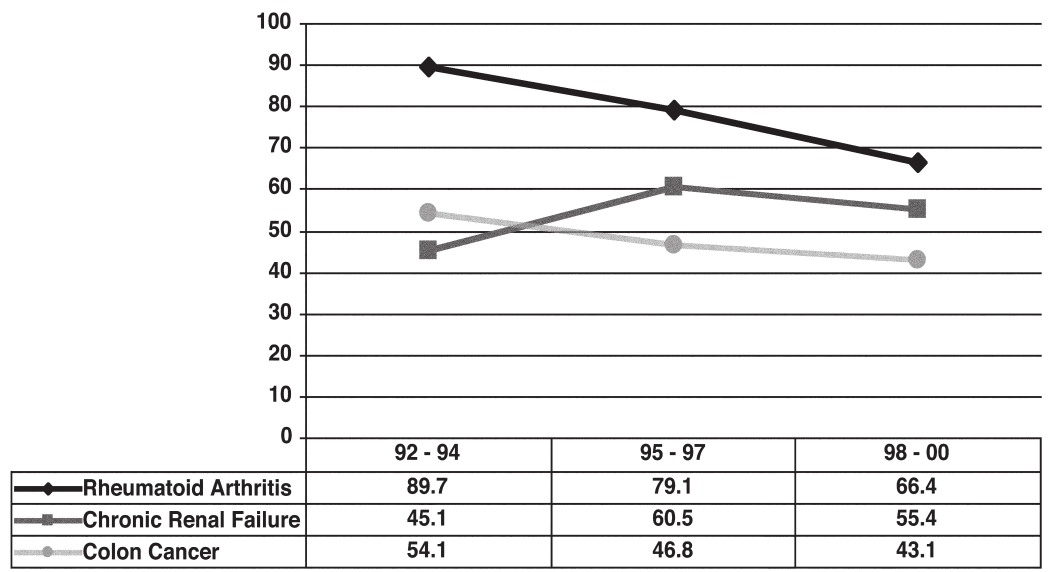

*Age-adjusted to the 2000 United States Standard Population

3-year period

Figure 6. Trend in incidence of diagnosis with selected conditions, MESA, 19922000.

Rate per 100,000 *

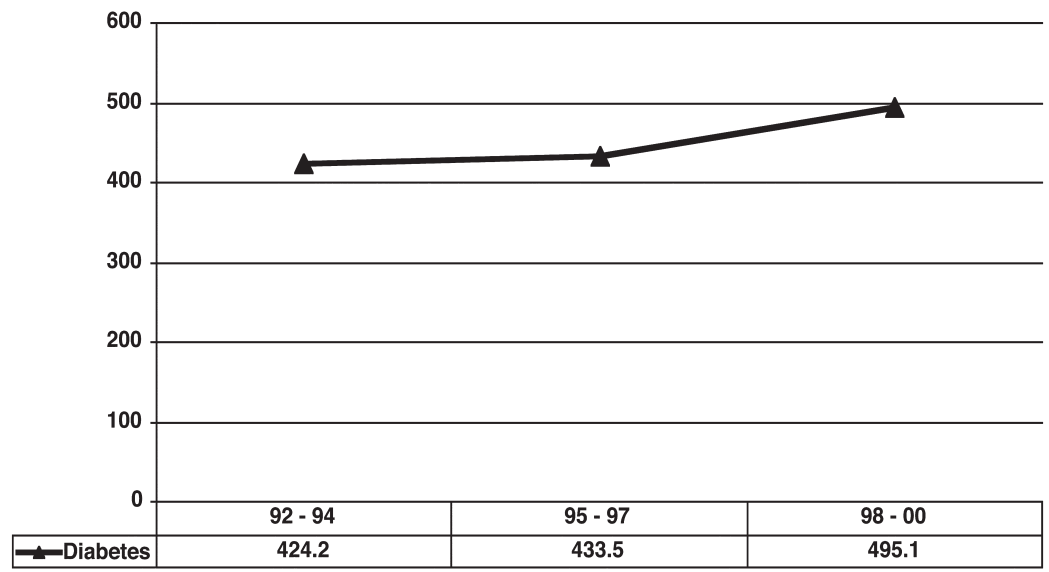

*Age-adjusted to the 2000 United States Standard Population 3-year period

Figure 7. Trend in incidence of diagnosis with diabetes, MESA, 1992-2000. 


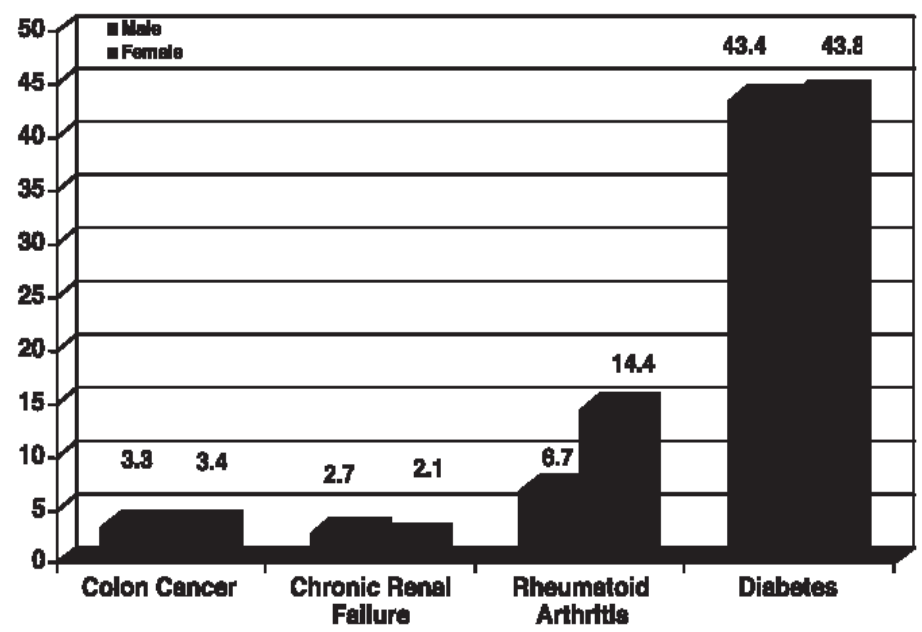

Figure 8. Prevalence of past diagnosis with selected chronic conditions, MESA, 12/31/2000, by gender.

renal failure leading to end stage renal disease. ${ }^{30}$ Finally, diabetes rates in MESA are slightly higher than previously reported rates from the United States, although a similar incidence increase has been observed. ${ }^{31}$ Due to the lack of adequate surveillance in the United States for many chronic diseases, ${ }^{2}$ routine estimation of disease frequency in MESA may provide a useful starting point.

Nevertheless, the rates presented in this report relied exclusively on ICD-9 diagnosis codes and a general validation rule, rather than individual case validation. The trend toward higher rates in MESA likely reflects a lack of specificity in case ascertainment. Additional data sources available at Marshfield Clinic improve on the specificity of case definitions when needed. These data sources, many of which are available electronically include clinical registries, laboratory data and patient medical charts. Previously published disease occurrence data typically relied on these additional data sources. On the other hand, general population rates based on patient encounters will also experience some pressure of underestimation, for not all people choose to seek care. It is anticipated that healthcare access and utilization will affect the observed rates of disease, especially for conditions that are less serious.

There are some alternative methods worth noting that can be used for determining disease frequency in MESA. While the residency tracking system can provide individually accrued person-time, denominators based on intercensal interpolations of United States decennial census counts for the MESA zip codes can also be utilized for incidence rate calculations. Population counts would be paired with numerator case counts based on ZIP code of residence at time of diagnosis. An additional correction would be warranted in such calculations, particularly for conditions that are not rare, whereby the census denominator would be reduced by the estimated number of people with a known disease history since they would not be at risk for an incident diagnosis. ${ }^{32}$ Also, the use of census-based calculations as a supplement can provide evaluation of the impact of inherent error in the residency tracking system data due to inexact dates of arrival into and departure from the region. The prevalence measure used in this paper, which is based on any past history of a diagnosis works well for many chronic conditions. However, for diseases that are acute, intermittent, or self-limited, a period prevalence that determines the proportion of the population diagnosed or receiving care for a particular condition over a given period of time may be more appropriate.

Marshfield Epidemiologic Study Area is a unique resource for population-based health research because it not only offers high capture of a well-defined population and their health events, but also provides individual tracking and estimates of accrued follow-up time. In the past decade, MESA has supported a number of informative studies of disease frequency that have broken new ground or have provided a rare opportunity to evaluate other important data sources.

\section{REFERENCES}

1. Hennekans CH, Buring JE. Epidemiology and Medicine. Little, Brown and Company, Boston. 1987; p 3.

2. Brownson RC, Remington PL, Davis JR, ed. Chronic Disease Epidemiology and Control. American Public Health Association, Washington, 1993; pp 9-10.

3. DeStefano F, Eaker ED, Broste SK, Nordstrom DL, Peissig PL, Vierkant RA, Konitzer KA, Gruber RL, Layde PM. Epidemiologic research in an integrated regional medical care system: the Marshfield Epidemiologic Study Area. J Clin Epidemiol 1996;49:643-652.

4. Nordstrom DL, Remington PL, Layde PM. The utility of HMO data for the surveillance of chronic diseases. Am J Public Health 1994;84:995-997.

5. Layde PM, Broste SK, Desbiens N, Follen M, Lynn J, Reding D, Vidaillet H. Generalizability of clinical studies conducted at tertiary care medical centers: a population-based analysis. J Clin Epidemiol 1996;49:835-841.

6. Nordstrom DL, Layde PM, Olson KA, Stueland D, Brand L, Follen MA. Incidence of farm-work-related acute injury in a defined population. Am J Ind Med 1995;28:551-564. 
7. Stueland DT, Lee BC, Nordstrom DL, Layde PM, Wittman LM. A population based case-control study of agricultural injuries in children. Inj Prev 1996;2:192-196.

8. Stueland DT, Nordstrom DL, Layde PM, Follen MA, Olson KA, Brand LM, Gunderson PD. Case control study of agricultural injuries to older farmers in central Wisconsin. J Am Geriatr Soc 1996;44:475-476.

9. Stueland DT, Lee BC, Nordstrom DL, Layde PM, Wittman LM, Gunderson PD. Case-control study of agricultural injuries to women in central Wisconsin. Women Health 1997;25:91-103.

10. Nordstrom DL, Layde PM, Olson KA, Stueland D, Follen MA, Brand L. Fall-related occupational injuries on farms. Am J Ind Med 1996;29:509-515.

11. Layde PM, Nordstrom DL, Stueland D, Wittman LB, Follen MA, Olson KA. Animal-related cccupational injuries in farm residents. J Agric Saf Health 1996;2:27-37.

12. Layde PM, Nordstrom DL, Stueland D, Brand L, Olson KA. Machine-related occupational injuries in farm residents. Ann Epidemiol 1995;5:419-426.

13. Zoch TW, Cleveland DA, McCormick J, Toyama K, Nordstrom DL. Football injuries in a rural area. Wis Med J 1996;95:570573.

14. Zoch TW, DeVries EO, Nordstrom DL. Incidence of roller sport injuries in a rural area. Acad Emerg Med 1997;4:330333.

15. Orejarena LA, Vidaillet H, DeStefano F, Nordstrom DL, Vierkant RA, Smith PN, Hayes JJ. Paroxysmal supraventricular tachycardia in the general population. J Am Coll Cardiol 1998;31:150-157.

16. Granada J, Uribe W, Chyou P, Maassen K, Vierkant R, Smith PN, Hayes J, Eaker E, Vidaillet H. Incidence and predictors of atrial flutter in the general population. J Am Coll Cardiol 2000;36:2242-2246.

17. Vidaillet H, Granada JF, Chyou P, Maassen K, Ortiz M, Pulido JN, Sharma P, Smith PN, Hayes J. A population-based study of mortality among patients with atrial fibrillation or flutter. Am J Med 2002;113:365-370.

18. Ruggles KH, Haessly SM, Berg RL. Prospective study of seizures in the elderly in the Marshfield Epidemiologic Study Area (MESA). Epilepsia 2001;42:1594-1599.

19. Nordstrom DL, DeStefano F, Vierkant RA, Layde PM. Incidence of diagnosed carpal tunnel syndrome in a general population. Epidemiology 1998;9:342-345.

20. Greenlee RT, Naleway AL, Vidaillet H. Incidence of myocardial infarction in a general population: The Marshfield Epidemiologic Study Area. WMJ 2002;101(7):46-52.

21. Belongia EA, Chyou P, Greenlee RT, Perez-Perez G, Bibb WF, DeVries EO. Diarrhea incidence and farm-related risk factors for Escherichia coli $\mathrm{O} 157: \mathrm{H} 7$ and Campylobacter jejuni antibodies in rural children. J Infect Dis 2003;187:14601468.

22. Naleway AL, Belongia EA, Kazmierczak JJ, Greenlee RT, Davis JP. Lyme disease incidence in Wisconsin: a comparison of state-reported rates and rates from a population-based cohort. Am J Epidemiol 2002;155:1120-1127.

23. Eaker ED, Vierkant RA, Konitzer KA, Remington PL. Cervical cancer screening among women with and without hysterectomies. Obstet Gynecol 1998;91:551-555.

24. Eaker ED, Wittman LM, Bergs RE. The Rural Women's Health Study: health and behavior of farm and nonfarm resident women. WMJ 2000;99(1):37-40.

25. McCarty C, Chyou P, Ziegelbauer L, Kempf D, McCarty D, Gunderson P, Reding D. A comparison of cardiovascular disease risk factors in farm and non-farm residents: the Wisconsin Rural Women's Health Study. WMJ 2002;101(7):34-39.

26. Naleway AL, Belongia EA, Greenlee RT, Kieke BA, Chen RT, Shay DK. Eczematous skin diseases and recall of past diagnoses: implications for smallpox vaccination. Ann Intern Med 2003;139:1-7.
27. Mendenhall W, Wackerly DD, Scheafer RL. Mathematical Statistics with Applications. Duxbury, Belmont, California, 4th ed., 1990; pp 358-364.

28. Ries LAG, Eisner MP, Kosary CL, Hankey BF, Miller BA, Clegg L, Edwards BK (eds). SEER Cancer Statistics Review, 1973-1998, National Cancer Institute. Bethesda, MD.

29. Kaipiainen-Seppanen O, Aho K. Incidence of chronic inflammatory joint diseases in Finland in 1995. J Rheumatol 2000;27:94-100.

30. Amend WJC and Vincenti FG. Chronic renal failure \& dialysis in Smith's General Urology, Tanagho EA, McAninch JW eds. McGraw-Hill, New York, 15th ed, 2000.

31. CDC. 1999 Diabetes surveillance report. Atlanta, Georgia: US Department of Health and Human Services, CDC, 1999. Available at http://www.cdc.gov/diabetes/statistics/index.htm. Accessed September 29, 2003.

32. Merril RM, Morris MK. Prevalence-corrected prostate cancer incidence rates and trends. Am J. Epidemiol 2002;155:148152. 